\title{
Voices of Youth and Emerging Adults on Suicide Prevention: Experiences and Expectations
}

\author{
Victoria Banyard ${ }^{1}\left[\right.$ [ $\cdot$ Kimberly J. Mitchell ${ }^{2} \cdot$ Lisa M. Jones ${ }^{2} \cdot$ Michele L. Ybarra $^{3}$
}

Accepted: 17 February 2022 / Published online: 1 March 2022

(c) Society for Prevention Research 2022

\begin{abstract}
Self-directed violence (SDV) is a significant public health issue for adolescents and emerging adults, and yet youth exposure to prevention messaging and youth perspectives on SDV prevention needs are understudied. The current study sought to better understand the ways in which a national sample of youth and emerging adults were exposed to suicide prevention programs or conversations. A sample of 1031 young people ages 13-23 were recruited nationally through social media. Survey questions asked about SDV prevention exposure. Open-ended questions asked youth to suggest additional information they desired about SDV. A majority of participants (87\%) reported that they had received prevention exposure from at least one source (i.e., family, online, attending a talk, or formal program) with few differences by demographic characteristics. However, sexual and gender minority (SGM) youth reported accessing more SDV prevention information online compared to other youth. Overall, youth had many ideas about what additional information they needed, including how to help someone at risk for SDV and how to access information about mental health. While the majority of youth are receiving some SDV prevention messages, there is variation in how they get this information, and survey participants still felt they were missing important information. Findings highlight the need to resource more comprehensive SDV prevention for youth and young adults.
\end{abstract}

Keywords Suicide $\cdot$ Prevention $\cdot$ Youth voices

\section{Introduction}

Self-directed violence (SDV), defined as any intentional act that can cause injury to one's self, including death (Crosby et al., 2011), is a significant public health issue for youth and emerging adults (Gould et al., 2003; Hawton et al., 2012). Exposure to SDV including a spectrum of survivorship also has significant impacts, especially for youth who may experience exclusion or marginalization by peers such as sexual and gender minority youth (Cerel et al., 2014; Mitchell et al., 2021). An evidence base for SDV prevention programs is growing (Bean \& Baber, 2011; Bell, 2015;

Victoria Banyard

Victoria.banyard@ rutgers.edu

1 Center for Research on Ending Violence, School of Social Work, Rutgers University, 123 Church Street, New Brunswick, NJ, USA

2 Crimes Against Children Research Center, University of New Hampshire, Durham, NH, USA

3 Center for Innovative Public Health Research, San Clemente, CA, USA
Center, 2020; Cooper et al., 2011) with a recent focus on training gatekeepers or bystanders who can help identify at-risk individuals and connect them to resources (Holmes et al., 2021). For example, the Sources of Strength program trains peers to promote awareness of SDV, including the value of seeking help (Wyman et al., 2010). This approach decreased SDV rates and improved social norms in one school district. Given that rates of SDV among adolescents and emerging adults have not shown the decline seen for other forms of violence, continued innovation is needed (Finkelhor et al., 2010; Hedegaard et al., 2018; Miron et al., 2019; Stone et al., 2018). Indeed, a growing body of work in prevention science highlights how there can be disconnects between knowledge of a problem and practice implementation (Pentz, 2004; Wandersman et al., 2008). Diffusion of an innovation is one aspect of implementation. Often studied in terms of individuals and how new prevention behaviors spread within a context like a school, diffusion also applies to policies and larger levels of change (Dearing \& Cox, 2018). Beyond curricula in specific schools, we currently know little about general SDV prevention exposure and diffusion. The current study sampled youth and young 
adults to examine who is most likely to receive SDV prevention messages and to describe the sources of prevention messages, and how such exposure is related to key prevention outcomes like gatekeeper helping.

An example of the utility of documenting the diffusion of prevention comes from the field of interpersonal violence. Finkelhor and colleagues conducted a broad study of violence prevention exposures among children (Finkelhor et al., 2014). The results documented widespread diffusion of violence prevention efforts as well as varied perceptions of their helpfulness. The study was useful in describing the range of violence prevention exposure and who might be more likely to receive it. The study also took some steps to document a range of impacts. We could not identify a similar study to examine the reach and potential impacts of suicide prevention programs though articles highlight its importance and evaluations of specific programs in discrete locations are numerous. Interestingly, one national study examined school principal's knowledge of state suicide prevention laws and school compliance with prevention mandates. The research found a great deal of variation and interesting correlates to explain it (including nature of the state law, perceptions of support, and available school/ community resources) (Smith-Millman \& Flaspohler, 2019). It seems important to also examine the reach of prevention programs from the perspective of youth and young adults.

Furthermore, program evaluation studies often document what participants find helpful as a component of process evaluation and implementation (Lindow et al., 2020). It seems important to get youth perspectives on prevention needs, especially given recent calls to better center the voices of older youth in prevention program design (Edwards et al., 2016). The current study surveyed a diverse sample of adolescents and emerging adults about whether they received SDV prevention information, and if so, how. Differences in prevention exposure were examined, including those based on social location as marked by demographics. Indeed, given prior research that indicates that sexual and gender minority youth are at high risk for SDV and SDV exposure, we were particularly interested in prevention exposure and attitudes of this group. As cross-sectional indicators of impact, variations by key prevention attitudes identified in previous SDV prevention studies including social norms for helping someone at risk of SDV, having resources for helping, and intent to help prevent SDV were examined in relation to SDV prevention exposure variables (Burnette et al., 2015). Overall, we hypothesized that SDV prevention-exposed participants would score higher on prevention supportive attitudes and resources. We also asked open-ended questions about what participants would like to learn in SDV prevention programming.

\section{Methods}

The Exploring Your YOU-niverse Study is a series of distinct national surveys of adolescents and emerging adults. The most recent version investigated exposure to selfdirected violence. A sample of 1031 youth and emerging adults (aged 13-23 years) was recruited between November 27, 2020, and December 4, 2020. The sample was $67.8 \%$ adolescents (ages 13-17), 76.04\% White, and 56.94\% sexual gender minority, and most participants $(n=528)$ said their family income was "similar to average" (see Table 1).

Participants were recruited through advertisements on Facebook and Instagram, though we did not track which participants came from which site. Facebook allows targeted ads based upon age and sex. Online ads encouraged youth and young adults to "have their voice heard" and "make a difference." Survey aims were not mentioned to reduce self-selection bias based upon interest in SDV. Those interested clicked on the online ad, which linked them to a secure survey website. The first page provided a study description and asked screening questions to determine eligibility. Those who were eligible (13-23 years of age, living in the USA, English speaking) were then asked to read an assent/consent form and to indicate their willingness to participate before continuing. A waiver of parental permission was granted for youth under the age of 18 because requiring parental consent could potentially unintentionally disclose their sexual experiences and/or sexual attraction to their parents. In some families, this could pose physical or emotional danger for the child. A waiver also is necessary to avoid fatal sampling bias in the SGM sample that would occur by only including those who are out to their parents (Cwinn et al., 2021). Our protocol met the requirements for 45 CFR 46116 . (f) and 45 CFR 46.408(c). Survey responses that suggested the respondent might be in a harmful situation were re-contacted by a clinical member of the research team, trained in telephone crisis counseling, whose responsibility was to provide targeted referrals.

Participants were given a \$5 Amazon gift code for completing the survey and links to general resources. Ineligible youth were directed to a web page that included links to general resources for youth (e.g., https://youngwomenshealth. org). To promote a diverse sample, demographic quotas were identified based on age, gender, and sexual orientation. Once the targeted number of participants in a particular group had been achieved (e.g., aged 13-17, cisgender girls), subsequent youth in this group who were otherwise eligible were deemed ineligible. The protocol was reviewed and approved by Pearl Institutional Review Board.

\section{Measures}

SDV prevention exposure was measured with five items. Two questions, adapted from Youth Internet Safety Survey 
Table 1 Participant characteristics by type of SDV prevention exposure (full sample $N=1031$ )

\begin{tabular}{|c|c|c|c|c|c|c|}
\hline \multirow[t]{2}{*}{ Characteristic } & \multirow{2}{*}{$\begin{array}{l}\text { All participants } \\
(N=1031) \\
n(\%)\end{array}$} & \multirow{2}{*}{$\begin{array}{l}\text { Exposure to SDV } \\
\text { prevention (any) } \\
(n=894) \\
n(\%)\end{array}$} & \multicolumn{4}{|c|}{ Type/source of prevention } \\
\hline & & & $\begin{array}{l}\text { From family } \\
(n=532) \\
n(\%)\end{array}$ & $\begin{array}{l}\text { From website } \\
(n=636) \\
n(\%)\end{array}$ & $\begin{array}{l}\text { Attended talk } \\
(n=596) \\
n(\%)\end{array}$ & $\begin{array}{l}\text { Took part in program } \\
(n=227) \\
n(\%)\end{array}$ \\
\hline \multicolumn{7}{|l|}{ Age } \\
\hline $13-17$ years & $699(67.8)$ & $602(86.1)$ & $373(53.4)$ & $411(58.8)^{* *}$ & $400(57.2)$ & $139(19.9)^{*}$ \\
\hline $18-3$ years & $332(32.2)$ & $292(87.9)$ & $159(47.9)$ & $225(67.8)$ & $196(59.0)$ & $88(26.5)$ \\
\hline \multicolumn{7}{|l|}{ Race } \\
\hline \multicolumn{7}{|l|}{ White } \\
\hline No & $247(24.0)$ & $205(83.0)^{*}$ & $113(45.7)^{*}$ & $144(58.3)$ & $145(58.7)$ & $56(22.7)$ \\
\hline Yes & $784(76.0)$ & $689(87.9)$ & $419(53.4)$ & $492(62.8)$ & $451(57.5)$ & $171(21.8)$ \\
\hline \multicolumn{7}{|l|}{ Black } \\
\hline No & $943(91.5)$ & $824(87.4)^{*}$ & $492(52.2)$ & $587(62.3)$ & $551(58.4)$ & $209(22.2)$ \\
\hline Yes & $88(8.5)$ & $70(79.5)$ & $40(45.5)$ & $49(55.7)$ & $45(51.1)$ & $18(20.5)$ \\
\hline \multicolumn{7}{|l|}{ Asian } \\
\hline No & 935 (90.7) & $815(87.2)$ & $491(52.5)$ & $577(61.7)$ & $541(57.9)$ & $204(21.8)$ \\
\hline Yes & $96(9.3)$ & $79(82.3)$ & $41(42.7)$ & $59(61.5)$ & $55(57.3)$ & $23(24.0)$ \\
\hline \multicolumn{7}{|l|}{ Mixed race } \\
\hline No & $923(89.5)$ & $803(87.0)$ & $473(51.3)$ & $574(62.2)$ & $531(57.5)$ & $206(22.3)$ \\
\hline Yes & $108(10.5)$ & $91(84.3)$ & $59(54.6)$ & $62(57.4)$ & $65(60.2)$ & $21(19.4)$ \\
\hline \multicolumn{7}{|l|}{ Hispanic/Latino ethnicity } \\
\hline No & $848(82.3)$ & $738(87.0)$ & $440(51.9)$ & $539(63.6)^{* *}$ & $482(56.8)$ & $191(22.5)$ \\
\hline Yes & $183(17.7)$ & $156(85.3)$ & $92(50.3)$ & $97(53.0)$ & $114(62.3)$ & $36(19.7)$ \\
\hline \multicolumn{7}{|l|}{ Sexual and gender identity } \\
\hline $\begin{array}{l}\text { Cisgender heterosexual } \\
\text { males }\end{array}$ & $203(19.7)$ & $162(79.8)$ & $110(54.2)$ & $97(47.8)^{* * *}$ & 109 (53.7) & $42(20.7)$ \\
\hline $\begin{array}{l}\text { Cisgender sexual minority } \\
\text { males }\end{array}$ & $242(23.5)$ & $208(85.9)$ & $109(45.0)$ & $143(59.1)$ & $146(60.3)$ & $57(23.5)$ \\
\hline $\begin{array}{l}\text { Cisgender heterosexual } \\
\text { females }\end{array}$ & $241(23.4)$ & $203(84.2)$ & $126(52.3)$ & $133(55.2)$ & $147(61.0)$ & $43(17.8)$ \\
\hline $\begin{array}{l}\text { Cisgender sexual minority } \\
\text { females }\end{array}$ & $167(16.2)$ & $155(92.8)$ & $97(58.1)$ & $125(74.9)$ & $102(61.1)$ & $48(28.7)$ \\
\hline $\begin{array}{l}\text { Gender minority afab/ } \\
\text { amab }^{\mathrm{a}}\end{array}$ & $178(17.3)$ & $166(93.3)$ & $90(50.6)$ & $138(77.5)$ & $92(51.7)$ & $37(20.8)$ \\
\hline \multicolumn{7}{|l|}{ Family income } \\
\hline Higher than average & $211(20.5)$ & $185(87.7)$ & $125(59.2)^{*}$ & $141(66.8)$ & $129(61.1)$ & $51(24.2)$ \\
\hline Similar to average & $528(51.2)$ & $463(87.7)$ & $273(51.7)$ & $318(60.2)$ & $308(58.3)$ & $113(21.4)$ \\
\hline Lower than average & $215(20.9)$ & $178(82.8)$ & $99(46.1)$ & $131(60.9)$ & $111(51.6)$ & $44(20.5)$ \\
\hline Not sure & $77(7.5)$ & $68(88.3)$ & $35(45.5)$ & $46(59.7)$ & $48(62.3)$ & $19(24.7)$ \\
\hline \multicolumn{7}{|l|}{ Status in school } \\
\hline Middle school (6-8 grade) & $164(15.9)$ & $132(80.5)$ & $80(48.8)$ & $88(53.7)^{* *}$ & $77(46.9)^{*}$ & $24(14.6)^{* *}$ \\
\hline High school (9-12 grade) & $581(56.3)$ & $506(87.1)$ & $318(54.7)$ & $349(60.1)$ & $343(59.0)$ & $123(21.2)$ \\
\hline $\begin{array}{l}\text { High school graduate (not } \\
\text { enrolled) }\end{array}$ & $58(5.6)$ & $53(91.4)$ & $31(53.5)$ & $36(62.1)$ & $39(67.2)$ & $10(17.2)$ \\
\hline Dropped out & $21(2.0)$ & $20(95.2)$ & $10(47.6)$ & $14(66.7)$ & $13(61.9)$ & $6(28.6)$ \\
\hline $\begin{array}{l}\text { Higher education (trade or } \\
\text { college) }\end{array}$ & $207(20.1)$ & $183(88.4)$ & $93(44.9)$ & $149(72.0)$ & $124(59.9)$ & $64(30.9)$ \\
\hline
\end{tabular}

Row percentages

${ }^{*} p \leq .05 ; * * \leq .01 ; * * * p \leq .001$ from chi-square tests

${ }^{a}$ Gender minority youth are not further stratified by sexual identity because only $2.3 \%(n=4)$ identified as heterosexual 
(YISS) (Wolak et al., 2006), focused on whether someone in their family had ever talked to them about people who want to hurt themselves or how to help. Items also asked whether they had been to a website or attended a talk about how to prevent suicide. One item (Finkelhor et al., 2014) asked more specifically if they had taken part in a specific program that taught people about what to do if someone they know wanted to hurt themselves. If yes, they were asked how helpful the program was (from (1) not helpful to (4) very helpful) and how much new information the program taught them (from (1) no new information to (4) all new information). Finally, participants were asked what they would want the adults in their life to talk to youth about, specific to suicide. Four response options were offered and participants could mark all that apply: (1) information on how to know if someone may want to hurt themselves; (2) how to help someone who may be thinking about hurting themselves; (3) where to find information about mental health; and (4) where to find information about how to prevent suicide. Participants were also given the option to write in something that was not covered in the above items.

To better understand variation among participants exposed to SDV prevention, several measures related to providing help or being an active gatekeeper/bystander were included.

Social norms around helping behaviors specific to SDV were modified from Aldrich et al. (2014). Participants were asked how much they agree or disagree that their closest friends think it is a good idea to get help for someone who wanted to hurt themselves. No more than $1 \%$ of data were missing on any one variable; these answers were recoded to the item mean. Response options ranged from (1) strongly disagree to (4) strongly agree. Items were combined to create a scale score $($ mean $=23.1, \mathrm{SD}=3.68)$. Items were summed and then divided by the number of items to produce an average score $(\alpha=0.75)$.

Bystander intent was queried using nine items adapted from the Aldrich et al. study (2014). Participants were told: "Now we have some questions about what you would do, if anything, if you knew someone who wanted to hurt themselves on purpose. By "hurt themselves on purpose," we mean wanting to kill or injure themselves in other ways, like by cutting or burning." They were told "Remember, there are no right or wrong answers here and it isn't always possible to help." Response options ranged from 1 (very unlikely) to 4 (very likely). Missing data was no larger than $1 \%$ for each variable and recoded as the item mean. Four separate avenues for intentions to help were queried: (1) use of external resources ( 2 items) (e.g., contact a crisis hotline or encourage the at-risk person to use a hotline or counseling) ( $\alpha=0.60$ ), (2) use informal adult supports ( 2 items) (e.g., encourage the at-risk person to talk to their family, or the participant talks to a helpful adult for advice) $(\alpha=0.60)$, (3) provide encouragement/support ( 2 items) (e.g., tell the atrisk person they matter or express worry) $(=0.47)$, and (4) get resources for oneself from a peer (peer support) (1 item) (i.e., talk to a friend about my worries). A fifth avenue asked about giving the person time to get better and represents a more passive response (Muehlenkamp \& Hagan, 2019).

Bystander resources. One question asked: "Do you have someone you can go to for advice if you are worried about a friend or family member hurting themselves on purpose?" (yes/no/decline to answer). We also asked whether they knew of a specific place, like a hotline or crisis center, that they could share with someone they think may want to hurt themselves on purpose (yes/no/decline to answer). For both items, decline to answer responses (3\% and $1 \%$, respectively) were coded as " $0 . "$

An adapted measure of social support (Zimet et al., 1988) had eight items, three referring to an adult family member and five referring to friends. Response options ranged from (1) very strongly disagree to (4) very strongly agree. Missing data was not higher than $0.87 \%$ and was replaced with individual item means. Items were combined to reflect a total social support score with higher values indicating more support $($ mean $=23.3, \mathrm{SD}=4.09)$ with good reliability $(\alpha=0.82)$.

Depressive symptoms. We used the Modified Depression Scale (MDS) (Dunn et al., 2012) to assess symptoms of depression. Participants were asked to report the frequency of six symptoms in the past month. We derived total scores by summing the 5-point Likert scale items (range: 5-25). Reliability for the scale was acceptable $(\alpha=0.79)$. Missing data ranged from 0.5 to $2.0 \%$ and was replaced with the item mean.

Demographic characteristics. Age was a continuous variable ranging from 13 to 23 years. Self-reported household income comprised three answer choices: lower than average, about average, and higher than average. For multivariate analyses, those who indicated their family income was "lower than average" were compared to all other youth. Youth reported their race (each was entered singly; for example, White versus all other) and ethnicity (coded as Hispanic versus other).

Gender identity was queried with the following response options: male; female; female-to-male (FTM)/transgender male/trans man; male-to-female (MTF)/transgender female/ trans woman; gender queer/non-binary/pangender; other (specify), I don't understand this question; and decline to answer. Sexual identity was measured with the following response options: gay, lesbian, bisexual, straight/heterosexual, questioning, queer, pansexual, asexual, other (specify), unsure, and decline to answer. Participants were allowed to endorse multiple options.

Youth were categorized into one of six groups based on their responses to the above questions and their identified 
sex at birth: (1) cisgender heterosexual males ( $n=192),(2)$ cisgender sexual minority males $(n=231)$, (3) cisgender heterosexual females $(n=232)$, (4) cisgender sexual minority females $(n=163),(5)$ gender minority assigned male at birth (AMAB) $(n=38)$ or assigned female at birth (AFAB) $(n=140)$. Gender minority AMAB and AFAB youth were combined due to low cell stability for AMAB participants. Cisgender refers to people who identify their gender as the same as the sex they were assigned at birth. Gender minority youth were not further categorized by their sexual identity because only a few identified as heterosexual, thereby resulting in an unstable analytical cell $(n=2)$.

\section{Data Analysis}

We first present the percentages of exposure to SDV prevention overall and from specific sources (family, website, talk, program); chi-square tests examined differences in these exposures by participant demographic characteristics. Next, among the subgroup of youth who attended an SDV prevention program $(n=227)$, we provided descriptive statistics regarding their perceived helpfulness of the program content and the amount of new information they learned. We then present data on what youth said they would like to know about SDV; qualitative coding of the openended responses for "something else" was conducted using content analysis with codes developed by the first author and a research assistant following guidelines for qualitative coding (Graneheim \& Lundman, 2004; Hsieh \& Shannon, 2005). All responses were coded by the research assistant and $50 \%$ were checked for consistency by the first author. Finally, five logistic regression models were estimated, one for exposure overall and four each with a different source of prevention education: (1) family (any versus none), (2) website (any versus none), (3) talk (any versus none), and (4) program (any versus none) as the outcome. Independent variables included social norms for helping someone at risk for SDV, intentions to help someone at risk for SDV, bystander resources (including social support), and youth demographic characteristics (race, ethnicity, sexual and gender identity, age and household income).

\section{Results}

\section{Exposure to SDV Prevention}

The majority $(86.7 \%)$ of the youth in this sample had been exposed to SDV prevention messages from at least one source: $61.7 \%$ from a website, $51.6 \%$ from a family member $(44.7 \%$ said a family member had talked to them about suicide more generally and $26.7 \%$ said a family member had talked to them about how to help someone at risk), $57.8 \%$ had been to a talk about suicide prevention, and $22.0 \%$ had attended a specific prevention program.

At the bivariate level, White youth were more likely to report any exposure to SDV prevention than non-White ( $87.9 \%$ vs. $83.0 \%, p=0.05$ ) while Black youth were less likely than non-Black youth $(79.5 \%$ vs. $87.4 \%, p=0.04)$. Differences were also noted by SGM identity, with more SGM youth reporting prevention exposure: $93.3 \%$ of gender minority youth, $92.8 \%$ of cisgender sexual minority females, $85.9 \%$ of cisgender sexual minority males, $84.2 \%$ of cisgender heterosexual females, and $79.8 \%$ of cisgender heterosexual males $(p<0.001)$ reported prevention exposure. No other differences were noted for overall prevention exposure (Table 1).

A few differences in sources of SDV prevention exposure were noted: White youth were more likely than non-White youth to have received prevention messages from family; this was also true of youth living in higher-than-average income households compared to less. Citing a website as a source of prevention was more common for older $(67.8 \%)$ versus younger $(58.8 \%)$ youth $(p<0.01)$, and less likely for cisgender males. Indeed, a majority of cisgender sexual minority females $(74.9 \%)$ and gender minority youth $(77.5 \%)$ cited this source. Older youth $(26.5 \%)$ were more likely than younger $(19.9 \%)(p<0.05)$ to say they had attended a specific program. Those in middle school (grades 6-8) were the least likely to have attended a talk or taken part in a specific program compared with youth in higher grades.

\section{What Youth Think About Program Content}

Among the subgroup of youth who had taken part in a specific program $(n=227), 30.1 \%$ said the program was very helpful and another $33.2 \%$ said it was somewhat helpful; only $9.7 \%$ said it was not helpful (Table 2). Most youth said they received at least some new information from the program $(83.2 \%) ; 15.9 \%$ said they received no new information and $4.0 \%$ said they received all new information. Further analyses (not shown in table) indicated no significant demographic differences between those youth who said the program was not/a little versus somewhat/very helpful.

\section{What Youth Want to Know About SDV Prevention}

Based on specific survey questions, more than three in four participants $(77.0 \%, N=792)$ wanted to know how to help someone who may be thinking about hurting themselves. Most also wanted to know where to find information about mental health $(63.0 \%, N=646)$, information on how to know if someone may want to hurt themselves $(61.0 \%, N=627)$, 
Table 2 What participants think about SDV prevention program content $(n=227)$

\begin{tabular}{ll}
\hline & $\boldsymbol{n}(\boldsymbol{\%})$ \\
\hline Helpfulness of program content & $22(9.7)$ \\
Not helpful & $60(26.5)$ \\
A little helpful & $75(33.2)$ \\
Somewhat helpful & $68(30.1)$ \\
Very helpful & $1(0.4)$ \\
Decline to answer & $36(15.9)$ \\
Amount of new information received in the prevention program & $114(50.4)$ \\
No new information & $65(28.8)$ \\
A little new information & $9(4.0)$ \\
Mostly new information & $2(0.9)$ \\
All new information & \\
Decline to answer &
\end{tabular}

and where to find information about how to prevent suicide (57.0\%, $N=584)$. Another 116 checked "other" and of these, 114 provided a qualitative response (see Table 3 for analysis of open-ended responses). Prevalent responses included wanting more accessible community resources; wanting more information about SDV, including the warning signs; wanting more skills about how to help someone, including SDV coping strategies; and wanting to help people feel less stigmatized by admitting SDV or seeking help.

\section{Regression Results Examining Correlates of Different Types of SDV Prevention Exposure}

We examined unique correlates with overall and different types of SDV prevention exposure using logistic regression (Table 4). Higher odds of exposure to any type of prevention was associated with knowing a supportive adult and having knowledge of crisis hotline information and lower odds with intending to seek help from a peer to prevent SDV. Youth from families with lower incomes were less likely to report prevention exposure, while cisgender sexual minority participants and gender minority participants were more likely to report overall prevention exposure. For all types of exposure, those who said that they knew an adult they could turn to for advice were significantly more likely to also say that they had been exposed to SDV prevention information across each of the four modes assessed: family $(\mathrm{aOR}=1.58, p=.004)$, a website $(\mathrm{aOR}=1.75, p=.001)$, a talk $(\mathrm{aOR}=1.62, p=.002)$, and taking part in a prevention program $(\mathrm{aOR}=1.52, p=.04)$. Intent to seek help from an adult was significantly related to SDV prevention exposure from family $(\mathrm{aOR}=1.14, p=.03)$ and attending a talk $(\mathrm{aOR}=1.15, p=.02)$. Having knowledge of a hotline or crisis center was associated with higher odds of being exposed to SDV prevention messaging from family $(\mathrm{aOR}=1.30, p=.05)$, online $(\mathrm{aOR}=2.45, p<.001)$, a talk $(\mathrm{aOR}=1.83, p<.001)$, or a specific program $(\mathrm{aOR}=2.39$,

Table 3 Responses to open-ended questions about other topics participants requested related to SDV prevention $(N=114)$

\begin{tabular}{|c|c|}
\hline Topic and quotes & $\%(N)$ \\
\hline $\begin{array}{l}\text { Accessing community resources (info on how to access and getting more access) } \\
\text { Quotes: "Who to go to when telling an adult isn't the best course of action" } \\
\text { "Better health services in the schools and communities that are free and confidential" }\end{array}$ & $14 \%(16)$ \\
\hline $\begin{array}{l}\text { Knowledge of warning signs and causes of SDV } \\
\text { Quotes: "Information to gauge the severity of the person's suicidality" }\end{array}$ & $24.6 \%(28)$ \\
\hline $\begin{array}{l}\text { Info and skills for how to help someone at risk for SDV } \\
\text { Quotes: "Strategies to help people who have depression that don't involve calling the police. I think my generation is rightfully } \\
\text { very hesitant to call the police, especially if the person involved is Black, given the lethal force that police have been known to use } \\
\text { against Black people struggling with mental health issues." } \\
\text { "How to create an emotional space to talk about dark thoughts, i.e., suicide" }\end{array}$ & $28.9 \%$ \\
\hline Coping skills for dealing with SDV thoughts and feelings & $21.9 \%(25)$ \\
\hline $\begin{array}{l}\text { Helping yourself so that you can help someone else } \\
\text { Quotes: "Coping with the fact that many people cannot and do not want to be saved." } \\
\text { "I think that we need to be on good mental footing first in order to help others." }\end{array}$ & $7 \%(8)$ \\
\hline $\begin{array}{l}\text { Building healthier relationships and more social support } \\
\text { Quotes: "The best thing you can do is make close friends that can help you cope with your issues." }\end{array}$ & $8.8 \%(10)$ \\
\hline $\begin{array}{l}\text { Strengths like emotion regulation skills, sense of mattering } \\
\text { Acceptance of one's feelings } \\
\text { Quote: "The importance of expression. Most people I know who have been suicidal or self-harm are those who were either } \\
\text { never taught to express their emotions and feelings, or they were told to repress them. Being taught about accepting how we are } \\
\text { imperfect is important." }\end{array}$ & $8.8 \%(10)$ \\
\hline $\begin{array}{l}\text { Changing norms so okay to ask for help and de-stigmatize SDV } \\
\text { Quote: "That people that hurt themselves or want to die aren't bad people or always at fault for how they feel/act." } \\
\text { "Getting rid of stigma behind getting help." }\end{array}$ & $13.2 \%(15)$ \\
\hline
\end{tabular}




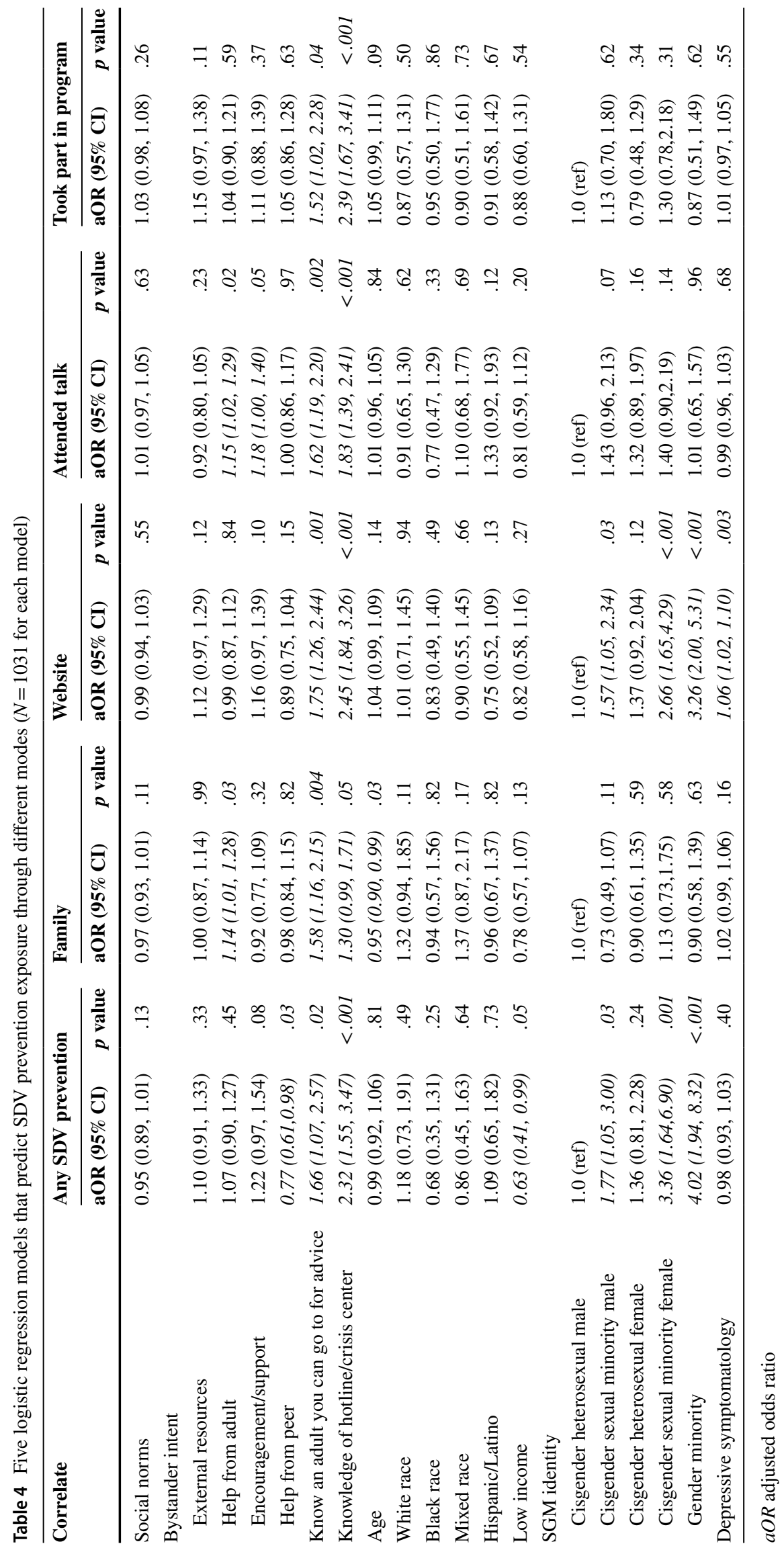


$p<.001)$. Older youth were less likely compared to younger to say they had received SDV prevention information from family ( $\mathrm{aOR}=0.95, p=.03$ ). Cisgender sexual minority males $(\mathrm{aOR}=1.57, p=.03)$, cisgender sexual minority females $(\mathrm{aOR}=2.66, p<.001)$, and gender minority youth $(\mathrm{aOR}=3.26, p<.001)$ were significantly more likely than cisgender heterosexual males to say they received SDV prevention from a website. Finally, higher depressive symptomatology scores were related to receipt of prevention through a website $(\mathrm{aOR}=1.06, p=.003)$.

\section{Discussion}

Findings from the current study show that youth and emerging adults desire more conversations about SDV prevention. SDV prevention messages are being diffused widely and using different mechanisms but may still not be reaching youth in low opportunity contexts nor including the range of skills young people want to learn. Receiving prevention messages was associated with outcomes including having knowledge of hotline/crisis services information and intent to go to adults for help if they were exposed to someone who was at-risk for SDV, gatekeeper outcomes that are a focus of SDV prevention (Hart et al., 2018; Holmes et al., 2021). Intending to get help from a peer was lower among the any prevention-exposed group perhaps because prevention encourages help-seeking from adults for this age group.

All forms of prevention exposure were more evident among participants who reported having an adult they felt they could count on for support though overall, formal prevention training was reported by less than a quarter of participants. Informal adult and community conversations may be particularly important for empowering and supporting young people and more work is needed to train adults and create supportive settings for this. This is consistent with previous work on the benefits of training significant adults to talk with young people about dating and sexual violence (Doucette et al., 2021). To date, gatekeeper programs for suicide prevention specifically focus on school personnel's response to at risk students (Wyman et al., 2008). These programs increase the skill of professionals like teachers who may be on the front lines of talking to youth, while also ensuring that settings like schools have protocols, policies, and resources in place to address the needs of at-risk youth who may be identified. Mental Health First Aid is an evidence-based training for adults and youth in communities to promote awareness of mental illness and peer support (Hart et al., 2018; Morgan et al., 2018) yet in one study, only $12 \%$ of school principals indicated their SDV prevention included community training (Smith-Millman \& Flaspohler, 2019). Next steps might involve co-training adults and young people together to not only provide skills for individuals seeking to help others but also to promote communities of support for the gatekeepers themselves. Creating intentional linkages between programs offered over the lifespan might enhance effectiveness as well including SDV prevention on college campuses to reach young adults (Sylvara \& Mandracchia, 2019).

Given the rise in gatekeeper training, we might have expected prevention exposure to be associated with social norms supportive of helping (either because those who see helping as supported by peers might seek out more prevention or because prevention programs might address norms) (Aldrich, 2015). Social norms about helping prevent SDV were unrelated to exposure to SDV prevention information in the current study. This could be because the prevention youth reported on surveys was focused on SDV knowledge and stigma reduction rather than norms around helping and it is likely that providing information about community resources like hotlines is a part of all SDV prevention work (Holmes et al., 2021; Morgan et al., 2018).

Participants had many suggestions about what they wanted to learn more about, including how to locate mental health resources and how to identify and help someone at risk for SDV. This last finding provides support for recent work that brings gatekeeper trainings to adolescents and young adults (Rallis et al., 2018; Wyman et al., 2010). The current study suggests that youth are eager for more nuanced and advanced training about how to identify and help peers in distress. They not only want to know more than what depression or suicide is but also specific ways to help. Beyond signs of risk, participants noted a desire for strengths-building resources including managing their own emotions as helpers and helping young people build positive social networks that can protect against SDV and work against the stigma of help-seeking (Banyard \& Hamby, 2021). Programs like Mental Health First Aid are promising but need to be more widely available (Hart et al., 2018) and may be enhanced by involving youth as prevention leaders (Boston Children's Hospital Neighborhood Partnerships Program, 2022).

Online prevention spaces are important. SGM participants were three times more likely than cisgender males and cisgender females to get information on SDV from a website. Indeed, studies of other prevention topics like sexual health highlight SGM individuals' preferences for online information (Flanders et al., 2017). This is an important area for further study and points to the need for making sure evidence-based prevention is easily available online. Researchers note that SGM youth also need tailored prevention resources (Marshall, 2016) and it may be that they feel these are more readily found in online spaces. Youth with depressed mood also indicated greater prevention exposure on websites perhaps encountering prevention information when seeking information about their own symptoms 
(Radovic et al., 2017). Such websites might co-locate information about helping oneself and helping others as a gatekeeper/bystander.

Prevention availability was another theme in the results. In open-ended responses, participants described the need for easier access to mental health services. Additionally, White participants were more likely to receive SDV prevention messaging in general and Black youth and participants living in low-income contexts were least likely to report this. This is concerning given that Black youth are a high-risk group for SDV (Bridge et al., 2018) and may live in communities that are under-resourced for prevention programming (Hamby et al., 2017; Smith-Millman \& Flaspohler, 2019). Prevention access inequity contributes to health outcome disparities. Prevention resources including funding, locating prevention specialists in schools, and programs like Mental Health First Aid that can train adults in communities (Hart et al., 2018; Morgan et al., 2018) need to be more equitably distributed across communities and engage community partners not only schools but also places where youth and adults spend time including faith-based organizations, athletic teams, community centers. Training for community leaders including school principals is needed. Research shows school principals often do not know about their state's suicide prevention laws and those who report access to funding and support for SDV prevention were more likely to have comprehensive programs (Smith-Millman \& Flaspohler, 2019). Policy context also matters as one study found states with laws requiring school SDV prevention training also had more comprehensive prevention strategies (Smith-Millman \& Flaspohler, 2019).

Limitations to the current study include not asking for specific details about the nature of prevention programs limiting understanding of the quality of information presented. Cross-sectional data prohibited inferences about the direction of observed effects and variations in the content of prevention messages may explain current findings. Questions such as "attended a talk about suicide prevention" were vague and could encompass a variety of activities. More refined measures need to be developed. Furthermore, this study explored prevention related to suicide and self-injury. While these behaviors often co-occur and share some common risk and protective factors, prevention of each may require different strategies. Further research about exposure to prevention of these issues separately is needed. The social media recruitment may have biased our sample in favor of youth with more of an online presence. Given that the data was gathered during the stressful COVID-19 pandemic, awareness of mental health issues like SDV may have been elevated in our sample and influenced results. The rich data obtained from open-ended responses points to the need for further qualitative research on SDV prevention.
Author Contribution VB participated in the design and coordination of the study and interpretation of data and wrote the first draft of the manuscript; KM participated in the design and coordination of the study and performed statistical analyses and data interpretation; MY participated in the design and coordination of the study and interpretation of data; LJ participated in interpretation of findings and implications for practice. All authors read and approved the final manuscript.

Funding This work was supported by NIH grant R01 HD083072b; research funds from the University of New Hampshire; and research funds from Rutgers University.

\section{Declarations}

Ethics Approval This study was performed in line with the principles of the Declaration of Helsinki. Appropriate mechanisms were in place to protect the children, such as localized referrals to mental health supports. The protocol was reviewed and approved by Pearl Institutional Review Board.

Consent to Participate Youth informed assent for participants ages 13-17 and informed consent from participants 18 and older were obtained. We requested and were granted a waiver of parental permission for participants under 18 years of age because our protocol met the requirements for 45 CFR 46 116. (f) and 45 CFR 46.408(c).

Conflict of Interest The authors declare no competing interests.

\section{References}

Aldrich, R. S. (2015). Using the theory of planned behavior to predict college students' intention to intervene with a suicidal individual crisis. Crisis, 2015, 332-337. https://doi.org/10.1027/0227-5910/ a000330

Aldrich, R. S., Harrington, N. G., \& Cerel, J. (2014). The willingness to intervene against suicide questionnaire. Death Studies, 38, 100-108. https://doi.org/10.1080/07481187.2012.738763

Banyard, V., \& Hamby, S. (2021). Strengths-based prevention: Reducing violence and other public health problems. American Psychological Association. https://doi.org/10.1037/0000267-000

Bean, G., \& Baber, K. M. (2011). Connect: An effective community-based youth suicide prevention program. Suicide and Life-Threatening Behavior, 41, 87-97. https://doi.org/10.1111/j.1943-278X.2010. 00006.x

Bell, K. (2015). Examining the effectiveness of gatekeeper training in suicide prevention (UMI 3712095) Doctoral dissertation, Texas Women's University

Boston Children's Hospital Neighborhood Partnerships Program. (2022). Break Free From Depression. https://www.childrenshospital.org/ breakfree. Accessed 11 February 2022

Bridge, J. A., Horowitz, L. M., Fontanella, C. A., Sheftall, A. H., Greenhouse, J., Kelleher, K. J., \& Campo, J. V. (2018). Agerelated racial disparity in suicide rates among US youths from 2001 through 2015. JAMA Pediatrics, 172, 697-699. https://doi. org/10.1001/jamapediatrics.2018.0399

Burnette, C., Ramchand, R., \& Ayer, L. (2015). Gatekeeper training for suicide prevention: A theoretical model and review of the empirical literature. Rand Health Quarterly, 5, 16. PMID: 28083369.

Center, S. P. R. (2020). A comprehensive approach to suicide prevention. Retrieved November 12, 2020 from https://www.sprc.org/ effective-prevention/comprehensive-approach 
Cerel, J., McIntosh, J. L., Neimeyer, R. A., Maple, M., \& Marshall, D. (2014). The continuum of "survivorship": Definitional issues in the aftermath of suicide. Suicide and Life-Threatening Behavior, 44(6), 591-600.

Cooper, G. D., Clements, P. T., \& Holt, K. (2011). A review and application of suicide prevention programs in high school settings. Issues in Mental Health Nursing, 32, 696-702. https://doi.org/ 10.3109/01612840.2011.597911

Crosby, A. E., Ortega, L., \& Melanson, C. (2011). Self-directed violence surveillance: Uniform definitions and recommended data elements, version 1.0. Atlanta (GA): Centers for Disease Control and Prevention, National Center for Injury Prevention and Control

Cwinn, E., Cadieux, C., \& Crooks, C. V. (2021). Who are we missing? The impact of requiring parental or guardian consent on research with lesbian, gay, bisexual, trans, two-spirit, queer/questioning youth. Journal of Adolescent Health, 68, 1204-1206. https://doi. org/10.1016/j.jadohealth.2020.07.037

Dearing, J. W., \& Cox, J. G. (2018). Diffusion of innovations theory, principles, and practice. Health Affairs, 37, 183-190. https://doi. org/10.1377/hlthaff.2017.1104

Doucette, H., Collibee, C., \& Rizzo, C. J. (2021). A review of parentand family-based prevention efforts for adolescent dating violence. Aggression and Violent Behavior, 58, 101548. https://doi. org/10.1016/j.avb.2021.101548

Dunn, E. C., Johnson, R. M., \& Green, J. G. (2012). The Modified Depression Scale (MDS): A brief, no-cost assessment tool to estimate the level of depressive symptoms in students and schools. School Mental Health, 4, 34-45. https://doi.org/10.1007/s12310-011-9066-5

Edwards, K. M., Jones, L. M., Mitchell, K. J., Hagler, M. A., \& Roberts, L. T. (2016). Building on youth's strengths: A call to include adolescents in developing, implementing, and evaluating violence prevention programs. Psychology of Violence, 6, 15. https://doi.org/10.1037/vio0000022

Finkelhor, D., Turner, H., Ormrod, R., \& Hamby, S. L. (2010). Trends in childhood violence and abuse exposure: Evidence from 2 national surveys. Archives of Pediatrics \& Adolescent Medicine, 164, 238-242. https://doi.org/10.1001/archpediatrics.2009.283

Finkelhor, D., Vanderminden, J., Turner, H., Shattuck, A., \& Hamby, S. (2014). Youth exposure to violence prevention programs in a national sample. Child Abuse \& Neglect, 38, 677-686. https://doi. org/10.1001/archpediatrics.2009.283

Flanders, C. E., Pragg, L., Dobinson, C., \& Logie, C. (2017). Young sexual minority women's use of the internet and other digital technologies for sexual health information seeking. The Canadian Journal of Human Sexuality, 26, 17-25. https://doi.org/10. 3138/cjhs.261-A2

Gould, M. S., Greenberg, T., Velting, D. M., \& Shaffer, D. (2003). Youth suicide risk and preventive interventions: A review of the past 10 years. Journal of the American Academy of Child \& Adolescent Psychiatry, 42, 386-405. https://doi.org/10.1097/01.CHI. 0000046821.95464.CF

Graneheim, U. H., \& Lundman, B. (2004). Qualitative content analysis in nursing research: Concepts, procedures and measures to achieve trustworthiness. Nurse Education Today, 24, 105-112. https://doi. org/10.1016/j.nedt.2003.10.001

Hamby, S., Blount, Z., Eidson, E., Smith, A., Rice, J., \& Bardi, C. A. . (2017). Breaking free from the web of violence: Asset-based approaches for boys and men of color. . R. f. B. a. M. o. Color. Available at http://www.equalmeasure.org/breaking-free-webviolence-asset-based-approaches-boys-men-color/. Accessed 12 November 2021

Hart, L. M., Morgan, A. J., Rossetto, A., Kelly, C. M., Mackinnon, A., \& Jorm, A. F. (2018). Helping adolescents to better support their peers with a mental health problem: A cluster-randomised crossover trial of teen Mental Health First Aid. Australian \& New
Zealand Journal of Psychiatry, 52, 638-651. https://doi.org/10. $1177 / 0004867417753552$

Hawton, K., Saunders, K. E., \& O'Connor, R. C. (2012). Self-harm and suicide in adolescents. The Lancet, 379, 2373-2382. https://doi. org/10.1016/S0140-6736(12)60322-5

Hedegaard, H., Curtin, S. C., \& Warner, M. (2018). Suicide rates in the United States continue to increase. NCHS Data Brief No. 309, Hyattsville, MD: National Center for Health Statistics

Holmes, G., Clacy, A., Hermens, D. F., \& Lagopoulos, J. (2021). The long-term efficacy of suicide prevention gatekeeper training: A systematic review. Archives of Suicide Research, 25, 177-207. https://doi.org/10.1080/13811118.2019.1690608

Hsieh, H.-F., \& Shannon, S. E. (2005). Three approaches to qualitative content analysis. Qualitative Health Research, 15, 1277-1288. https://doi.org/10.1177/1049732305276687

Lindow, J. C., Hughes, J. L., South, C., Gutierrez, L., Bannister, E., Trivedi, M. H., \& Byerly, M. J. (2020). Feasibility and acceptability of the youth aware of mental health (YAM) intervention in US adolescents. Archives of Suicide Research, 24, 269-284. https://doi.org/10.1080/13811118.2019.1624667

Marshall, A. (2016). Focus: Sex and gender health: Suicide prevention interventions for sexual \& gender minority youth: An unmet need. The Yale Journal of Biology and Medicine, 89, 205. PMID: 27354846

Miron, O., Yu, K.-H., Wilf-Miron, R., \& Kohane, I. S. (2019). Suicide rates among adolescents and young adults in the United States, 2000-2017. JAMA, 321, 2362-2364. https://doi.org/10.1001/jama. 2019.5054

Mitchell, K. J., Banyard, V., Goodman, K. L., Strøm, I. F., \& Ybarra, M. L. (2021). Exposure to suicidal behavior and social support among sexual-and gender-minority youth. Pediatrics, 147(4). https://doi. org/10.1542/peds.2020-033134

Morgan, A. J., Ross, A., \& Reavley, N. J. (2018). Systematic review and meta-analysis of Mental Health First Aid training: Effects on knowledge, stigma, and helping behaviour. PLoS ONE, 13, e0197102. https://doi.org/10.1371/journal.pone.0197102

Muehlenkamp, J. J., \& Hagan, C. R. (2019). Factors predicting intent to intervene with a potentially suicidal peer. Archives of Suicide Research, 1-15. https://doi.org/10.1080/13811118.2019.1635933

Pentz, M. A. (2004). Form follows function: Designs for prevention effectiveness and diffusion research. Prevention Science, 5, 23-29. https://doi.org/10.1023/B:PREV.0000013978.00943.30

Radovic, A., DeMand, A. L., Gmelin, T., Stein, B. D., \& Miller, E. (2017). SOVA: Design of a stakeholder informed social media website for depressed adolescents and their parents. Journal of Technology in Human Services, 35, 169-182. https://doi.org/10. 1080/15228835.2017.1347552

Rallis, B. A., Esposito-Smythers, C., Disabato, D. J., Mehlenbeck, R. S., Kaplan, S., Geer, L., \& Meehan, B. (2018). A brief peer gatekeeper suicide prevention training: Results of an open pilot trial. Journal of Clinical Psychology, 74(7), 1106-1116. https://doi. org/10.1002/jclp. 22590

Smith-Millman, M. K., \& Flaspohler, P. D. (2019). School-based suicide prevention laws in action: A nationwide investigation of principals' knowledge of and adherence to state school-based suicide prevention laws. School Mental Health, 11, 321-334. https:// doi.org/10.1007/s12310-018-9287-y

Stone, D. M., Simon, T. R., Fowler, K. A., Kegler, S. R., Yuan, K., Holland, K. M., Ivey-Stephenson, A. Z., \& Crosby, A. E. (2018). Vital signs: Trends in state suicide rates-United States, 19992016 and circumstances contributing to suicide-27 states, 2015. Morbidity and Mortality Weekly Report, 67, 617. https://doi.org/ 10.15585/mmwr.mm6722a1

Sylvara, A. L., \& Mandracchia, J. T. (2019). An investigation of gatekeeper training and self-efficacy for suicide intervention among 
college/university faculty. Crisis, 40, 383-389. https://doi.org/10. 1027/0227-5910/a000577

Wandersman, A., Duffy, J., Flaspohler, P., Noonan, R., Lubell, K., Stillman, L., \& Saul, J. (2008). Bridging the gap between prevention research and practice: The interactive systems framework for dissemination and implementation. American Journal of Community Psychology, 41, 171-181. https://doi.org/10.1007/ s10464-008-9174-z

Wolak, J., Mitchell, K., \& Finkelhor, D. (2006). Online victimization of youth: Five years later. N. C. f. M. a. E. Children accessed from http://unh.edu/ccrc/pdf/CV138.pdf. Accessed 7 October 2020

Wyman, P. A., Brown, C. H., Inman, J., Cross, W., Schmeelk-Cone, K., Guo, J., \& Pena, J. B. (2008). Randomized trial of a gatekeeper program for suicide prevention: 1-year impact on secondary school staff. Journal of Consulting and Clinical Psychology, 76, 104. https://doi.org/10.1037/0022-006X.76.1.104
Wyman, P. A., Brown, C. H., LoMurray, M., Schmeelk-Cone, K., Petrova, M., Yu, Q., Walsh, E., Tu, X., \& Wang, W. (2010). An outcome evaluation of the Sources of Strength suicide prevention program delivered by adolescent peer leaders in high schools. American Journal of Public Health, 100, 1653-1661. https://doi. org/10.2105/AJPH.2009.190025

Zimet, G. D., Dahlem, N. W., Zimet, S. G., \& Farley, G. K. (1988). The multidimensional scale of perceived social support. Journal of Personality Assessment, 52, 30-41. https://doi.org/10.1207/ s15327752jpa5201_2

Publisher's Note Springer Nature remains neutral with regard to jurisdictional claims in published maps and institutional affiliations. 